\title{
Plegados del cuidado. La ciudadanía y la ciudad en Las cosas nuevas de Ennio Moltedo*
}

\author{
Sergio Holas-Véliz \\ Adelaide University, Australia \\ sergio.holas@adelaide.edu.au
}

\begin{abstract}
Resumen
Este ensayo explora las complejas relaciones que se establecen entre arquitectura, ciudad, civilidad y cuidado en Las cosas nuevas (2011), de Ennio Moltedo. La práctica poética de Moltedo se inscribe como un cuestionamiento a las grandes transformaciones (globales) asociadas al neoliberalismo, cuya primera puesta en movimiento se llevó a cabo en Chile durante la última dictadura. Pero también pone en relación una visión arquitectural de la ciudad y el cuidado de ésta en su pliegue interior (el ciudadano) y en su pliegue exterior (la ciudad como lugar).
\end{abstract}

Palabras clave

Poesía, ciudad, cuidado de la ciudad, cuidado de sí mismo, pliegue.

Folding Carefully. Citizenship and the City in Las cosas nuevas, by Ennio Moltedo

\begin{abstract}
This essay explores the complex relationships between architecture, city, civility, and care in Las cosas nuevas (2011), by Ennio Moltedo, one of Valparaíso's foremost poets. Moltedo's poetic practice questions the global transformation brought forth by Chilean neoliberalism. He also produces an architectural vision of the city and how it is cared for, both on an intimate level (the citizen) and on an exterior level (the city as a place). In this way, a lack of care comes to light within both the individual and the city.
\end{abstract}

Keywords

Poetry, city, care of the city, care of self, folding.

* Recibido: 29 de marzo de 2016 / Aceptado: 17 de mayo de 2016. 


\section{Dobrando com cuidado. Cidadania e Cidade em Las cosas nuevas,} de Ennio Moltedo.

Resumo

Este ensaio explora as complexas relações entre arquitetura, cidade, civilidade e cuidado em Las cosas nuevas (2011), de Ennio Moltedo, um dos maiores poetas de Valparaíso. A prática poética de Moltedo questiona a transformação global trazida pelo neoliberalismo chileno. Ele também produz uma visão arquitetônica da cidade e como ela é cuidada, tanto em um nível íntimo (o cidadão) e em um nível exterior (a cidade como um lugar). Desta forma, é revelada uma falta de cuidado tanto no indivíduo como na cidade.

\section{Palavras-chave}

Poesia, cidade, cuidado da cidade, cuidado de sí mesmo, dobra. 
Para mí, los artistas de cualquier tipo [...] son los órganos de percepción de una sociedad o especie. Yo pienso que algunas personas son como sensores: así como nosotros usamos órganos como los ojos, las manos y los oídos como sensores, así, en la raza humana hay hombres y mujeres que aprehenden. [El] sensor es un ser profundamente social debido a la perspicacia de sus percepciones. Yo creo que esta función es extremadamente importante para la sociedad (Virilio cit. Armitage, 2001: 152).

\section{Sobre grandes transformaciones y prácticas artísticas}

La práctica poética de Ennio Moltedo tiene un contexto mucho más amplio de lo que generalmente se le reconoce: el de las grandes transformaciones sufridas por las culturas tradicionales durante la primera parte del siglo XX; y el período de readecuación del sistema-mundo post Segunda Guerra Mundial, en especial desde los años 1960 en adelante, cuando los Estados Unidos toman el relevo del proyecto imperial inglés y tienen lugar el surgimiento y la consolidación del neoliberalismo (la sociedad como mercado), del cual los chilenos continuamos siendo conejillos de Indias. En nuestro país, en efecto, se siguen experimentando las ya no tan nuevas teorías de mercadotecnia de las luminarias del reduccionismo económico que, hoy en día, más florece mientras más se hunde. En realidad, Ennio Moltedo toma el relevo de otros poetas que ya habían entrado en contacto con estos procesos, ya que, en Chile, durante la primera mitad del siglo XX, fue Violeta Parra quien vivió estos dramáticos y destructivos acontecimientos en los que la vida del campo y sus ecologías de saberes dejaron de ser legítimos para el nuevo hombre de las grandes urbes industriales. Con una lucidez única, ella supo resistir en forma afirmativa esta manera de desvivir/nos que llamamos modernidad (Holas, 2008; Castillo, 2003).

Pero Chile no ha sido un caso aislado, sino que sus elites han tomado un activo rol en las transformaciones que, a nivel mundial, se han vivido prácticamente en todos lados. En Europa misma, después de la Segunda Guerra Mundial, las antiguas ciudades habían sido destruidas y las que habían sobrevivido se encontraban bajo el ataque de los burócratas del nuevo urbanismo, acontecimiento clave que hizo desaparecer para siempre las avenidas, los pasajes y, con ello, las típicas maneras de asociarse, de sentir y de vivir de los habitantes de los barrios, en los antiguos cascos urbanos. En París, Guy Debord asoció este proceso con el origen de la sociedad del espectáculo en la cual vivimos nosotros hoy día. Allí y en ese entonces, formó la Internacional Situacionista, y le declaró la guerra al proyecto de renovación urbanística del antiguo París a manos de los nuevos burócratas (Andreotti et al., 1996; McDonough, 2009; Sadler, 1998), los que hicieron desaparecer áreas completas y, con ello, sus variadas formas de vida, en nombre del 
desarrollo no de los que allí vivían, sino de la verdad superior de las manos invisibles de siempre (economistas y empresarios de variados ámbitos). En ambos casos, el chileno y el francés, también innumerables otros, por ejemplo, la eliminación de los cascos antiguos del centro de ciudades en Asia, en que China es el mayor ejemplo de desarrollo, es decir, de destrucción de modos de vida; allí, como en otros también, donde el criterio superior siempre ha sido el del burócrata urbanista que, íntimamente atado al liberalismo económico, funciona como una máquina de guerra que va derribando barrio tras barrio, reinscribiendo la dominación y la dependencia en el corazón de los ciudadanos, de tal manera que su saber-vivir sea destruido y la guerra se continúe por diferentes medios (las nuevas tecnologías telemáticas), ad infinitum o mientras dure.

Este mismo proceso de debilitamiento y negación de sentires y saberes que desaparecen junto con la destrucción del lugar y que tiene implicaciones tanto para la ciudad material (externa) como para la ciudad espiritual (interior), es lo que viene explorando en sus plegados la poesía de Ennio Moltedo. Su mirada se enfoca en lo que está desapareciendo frente a sus ojos, para que sus lectores lo podamos ver, es decir, para que seamos conscientes de lo que estamos viendo por última vez o ya hemos perdido. Dice Ferlinghetti que siempre "(I)a vida poética de la ciudad, nuestra vida subjetiva, la vida subjetiva del individuo, está constantemente bajo el ataque de todas las fuerzas de la civilización material" (2001: 13). En Moltedo, la vida espiritual es traída a la mano en la ciudad y sus lugares, es decir, el espíritu toma forma material, se materializa en la ciudad en la que el poeta vive. Ésta es una visión que relaciona lo que de otra manera es separado en el vivir compartimentalizado de los quehaceres. Es en este sentido que la vida espiritual, la vida del individuo, la vida interior, la vida poética o, simplemente, la vida está siempre luchando contra las fuerzas de la logística de la muerte, disfrazada de las imágenes del cacareo telemático y de la banalidad del espectáculo de las nuevas cosas. El poeta es el cuidador que tiene la llave del reino de este mundo, para recordarle al lector/a el tesoro (inmaterial) guardado en su corazón, si es que éste desea saber. Escribe Moltedo en Las cosas nuevas:

Dejo en tus manos este objeto único que extraviaste en otro tiempo y que hoy he recuperado: la llave que protege el pasado secreto. Pequeña, arañada por el trajín de los años, por el silencio, ahora te la devuelvo como signo capaz de abrir o cerrar otra vez tu corazón (Poema 8).

El poema es la llave que hace algo en la arteriosclerosis (materialización de una placa de grasa, colesterol, calcio reduciendo el flujo de oxígeno por la sangre a los órganos) generalizada de la modernidad: reintroduce el flujo de oxígeno para permitir recordar qué somos. La poesía es la llave de la casa. Sin poesía, no hay vida espiritual. El lenguaje poético es la clave que abre un habitar con sentido afirmativo de la vida. 


\section{Sobre una relación entre la arquitectura y la poesía}

En 1997, al responder a una pregunta sobre el significado de la poesía, Moltedo comenta que poesía y arquitectura tienen una íntima relación, ya que "(e)l mundo es un nido en el espacio y debe ser poético" (Herrera, 1997). Este aspecto común entre arquitectura y poesía, el ayudar en la creación del espacio, el lugar, la casa del hombre, es lo que me propongo brevemente explorar en el libro Las cosas nuevas, de Ennio Moltedo.

Si bien la arquitectura trabaja el espacio y ayuda a convertirlo en lugar, el concepto de espacio es de una abstracción que le aprovecha más al arquitecto que al poeta, por la simple razón de que la poesía, como lo ha señalado Heidegger, tiene más que ver con la manera de habitar el espacio que con el espacio per se. Lo que a Moltedo importa es lo que él llama "nido", cuya etimología latina es nidus, del indoeuropeo nizdo, que significa "donde los pájaros se sientan" y es parte de la familia en la que encontramos también la palabra "nicho". "Nido", "nicho" y "anidar" tienen una raíz común. En la definición de "nido", que es la "estructura hecha por un pájaro para poner en ella sus huevos y criar a sus pollos" (Gómez de Silva: 481), hay dos aspectos que para este argumento son relevantes: primero, que el "nido" es la estructura hecha para poner los huevos; segundo, que, además, en ella se crían los pollos. El primero de estos dos aspectos corresponde a la arquitectura, ya que ésta edifica y articula el espacio donde se levanta la polis; el segundo remite a la poesía (y no sólo a la ley y a la norma, que más bien funcionan en la superficie de las cosas), que ayuda en la buena crianza a edificar al ciudadano. Estos dos aspectos del edificar son claves en lo que refiere a la construcción del espacio exterior de la polis, la ciudad-estado, y el espacio interior del ciudadano, la civitas, la civilidad. "Anidar" referiría a este arte de construir, es decir, de edificar tanto la ciudad como también al ciudadano. Al construir, en consecuencia, no sólo se construye un objeto externo a la acción misma de construir, sino que me trae a la mano en el saber-hacer del objeto que levanto a la distinción, a la existencia. Al construir, la acción de construir distingue tanto el objeto como el sujeto, ya que estos emergen en esa distinción que hacemos en el lenguaje y, de esta manera, vamos delimitándonos y nos levantamos así, trayendo a la mano nuestro mundo, a la existencia. En otras palabras, la dicotomía desaparece como tal, ya que el énfasis es puesto en el hecho de que, al hacer la distinción, traemos a la mano la presencia/existencia de algo. "Anidar" remitiría al arte de saber hacer el "nido", la casa, la ciudad, como también al arte de "criar", es decir, de enseñar la sabiduría del "buen vivir". Pero esto debe vivirse, es decir, en el cómo vivimos traemos a la mano un lugar, una pieza propia, única, histórica, personal, social, comunitaria, y así se va articulando también la polis, el "nido" a que hace referencia Ennio Moltedo, de una manera circular, puesto que un aspecto implica el otro de manera recurrente y afirmativa de vida. Por ello, el poeta 
puede aseverar: "En el espacio impongo un mundo más cercano o un principio de camino que conduce a la realidad nunca vista" (Moltedo, 2011: 98). El poeta, así, va trayendo a la mano, va construyendo con concreto azul la línea azul del horizonte, la línea del lápiz de pasta azul, una línea poética que "conduce a la realidad nunca vista" (98).

\section{Hacia una estética de memorias y desapariciones}

Hemos visto que ambos aspectos, la polis y la civitas, son claves para la salud tanto de la ciudad exterior como de la interior. Hemos afirmado, también, que estos aspectos se van modificando de manera recurrente y circular, al estar implicados el uno en el otro, y que la decadencia de la ciudad exterior necesariamente implica una decadencia de la ciudad interior, es decir, del ciudadano. En los plegados de Ennio Moltedo, esta articulación es la que tiene la mayor de las importancias, pues nos permite reflexionar sobre el tejido que todos hacemos en nuestros quehaceres diarios de la ciudad interior (las estancias del individuo), en su relación con la ciudad exterior (las estancias materiales y sociales). De allí su crítica a la falta de cuidado, la destrucción y la desaparición constantes de lugares familiares, históricos, significativos, así como al impacto de estas desapariciones de las señas de la ciudad externa -por ejemplo, las de la estación Barón, el balneario Recreo, la Playa Peñaloza, la Plaza Aníbal Pinto, la Fuente de Neptuno, la Compañía Inglesa № 11- y sus efectos en la subjetividad, la memoria y el sentido de orientación, pertenencia y cuidado de los objetos culturales de los porteños y viñamarinos.

El tema de las desapariciones de personas durante la última dictadura tiene una carga especial en algunos plegados de Moltedo (Poemas 39, 42, 59, 65). El juego que hace con el término "desaparición" es constante y remite a ambas ciudades constituyentes de la matriz biológico-cultural (Maturana, 2008). Los desaparecidos son aquellos que fueron muertos por la dictadura, como también los lugares que el nuevo Chile destruye con su falta de cuidado y su mirada perdida en un futuro que no emerge de nuestro saber-hacer, sino que es diseñado en abstracto en centros imperiales (Mignolo, 2000) que no conocen la peculiaridad de la polis ni de la civitas de estos lares. Cada vez que un lugar desaparece, también vamos desapareciendo nosotros, los habitantes de este lugar. En otras palabras, la transdictadura (Flores, SF) sigue actuando cuando, al destruir nuestros lugares, nuestras memorias, nuestras historias, nos vamos destruyendo a nosotros mismos con la vaga y falsa idea de que, al imitar al personaje de ojos azules, nuestros ojos cafés se tornarán, por arte de magia, azules también. Ésta es la pobreza de la endocolonización a la que se nos somete, la "Pacificación" de los chilenos que nos recuerda Elicura Chihuailaf (1999) y a la que Moltedo refiere una y otra vez: la pobreza de la mirada que le damos a la ciudad en la que vivimos, que nos hace 
devaluar los objetos culturales que emergen o desaparecen en nuestro propio quehacer y, con ello, también, nuestro propio quehacer como sociedad y la imagen que hemos creado de nosotros mismos. En este sentido, la dictadura, al ser internalizada se ha convertido en transdictadura: seguimos mirando con desprecio, a menos, el mundo que hacemos con nuestro vivir y, por ende, miramos, por el contrario, con grande y ciega admiración los valores, modelos, imágenes, estándares, instituciones y diseños imperiales de la ciudad global que, siempre omnipresente, no tiene fundaciones en ningún lugar, excepto en la acumulación y la multiplicación del capital financiero. Es en este sentido que Walter Benjamin puede aseverar que "(n)os hemos hecho pobres. Hemos ido entregando una porción tras otra de la herencia de la humanidad, con frecuencia teniendo que dejarla en la casa de empeño por cien veces menos de su valor para que nos adelanten la pequeña moneda de lo 'actual'” (1982: 173).

\section{El sistema del espectáculo y la pérdida del sentido de lo real}

En el sentido señalado, la percepción ha sido capturada por las tecnologías visuales y articulada de tal forma que funcione como dispositivo colonizador, proponiendo sólo ciertos modelos de la belleza, el buen hacer, el buen vivir, el parecer, el ser significativo, el ser inteligente, el tener éxito, el vestirse bien, el moverse correctamente, etcétera; es decir, como dispositivo reductor de las diversas ecologías visuales reales a manos de la industria militar, la que continúa su quehacer destructor por otros medios (las nuevas tecnologías virtuales y de vigilancia), emergidos en el período que va entre la Primera y Segunda Guerra Mundial, puesto que "el sistema de las estrellas y el de los símbolos sexuales fueron el resultado de una logística perceptual no anticipada que se desarrolló intensamente en cada campo durante la Primera Guerra Mundial" (Virilio, 1989: 29). Esta captura de cada aspecto del mundo de la vida, incluyendo los flujos de recursos naturales, está asociada al desarrollo en el campo de las tecnologías de la visión (las cámaras) en la logística militar, como también en su asociación con la industria del cine. El mundo de las cosas nuevas es, fundamentalmente, un mundo en el que la logística, es decir, la permanente preparación para la guerra de imágenes, está omnipresente en el aquí y el ahora de nuestras vidas, gracias a las tecnologías telemáticas (poemas 52, 61, 97, 114) y de tiempo real. A esto se refiere Humberto Maturana cuando reflexiona sobre el carácter patriarcal de nuestra cultura global (Maturana y Verden-Zöller, 1993; Maturana, 1995). A esto se refiere también el poeta cuando, por ejemplo, apela a los jóvenes y les dice:

Jóvenes (entre montañas o a la orilla del mar), será necesario superar la niebla o la bruma de los días. Sus mayores predicaron la muerte nocturna y hoy se parapetan bajo tiendas corporativas y la asistencia, en todo momento, de Evelyn y heraldos armados. La paz se verá, a su vez, resguardada a distancia por el signo de la caballería calavera. 
Jóvenes (entre construcciones y bloques ex jardines), les aviso que todas las promesas de oradores y medios -superiores y rasos- son falsas y de intención siniestra. Cuidado: en el largo territorio la tarde demora más de lo acostumbrado y su sombra cubre el país para volver a dormirlo (poema 71).

Como cuidador, el poeta apela a la juventud para que no acepte las falsas promesas y siniestras intenciones de sus mayores (poemas 5, 13, 90). Es una apelación que llama a cuidar ambas ciudades, a estar despiertos ante la sombra que cubre todo y presenta otra imagen (una realidad de segundo grado, mediática, que es tomada por la cosa misma) que duerme, con su efecto hipnótico, al país. Esta es una apelación a cuestionar el orden de los mayores, como lo hiciera también Carlos Droguett en su novela Matar a los viejos (2001), ya que la sociedad del espectáculo tiene sus fundamentos en la noche eterna de Chile (Moltedo, 1999), es decir, en la dictadura permanente (Manns, 1999) o transdictadura. EI poeta llama a "superar la niebla o la bruma de los días", es decir, la niebla mediática de los que "predicaron la muerte" y que hoy recurren a "Evelyn y los heraldos armados" manteniendo la logística, la preparación, para la guerra contra aquellos que desean percibir qué hay más allá de la imagen mediática. Se trata de luchar contra el efecto picnoléptico de los medios de comunicación (Redhead, 2004: 5), es decir, contra la muerte temporal que producen la televisión y los medios telemáticos en general de la sociedad del espectáculo, de la farándula. Contra el poder de este nuevo sol, luz artificial de los medios de comunicación que capturan la percepción y la envuelven en una bruma picnoléptica que hace posible el descuido y desaparecimiento del lugar, por ende, de las raíces, la memoria, la historia y el hombre político, la poesía de Moltedo llama a la necesidad de abrir la polis y la civitas hacia otro horizonte, más allá del espectáculo. Se trata de ir más allá de la mirada complaciente y de autosatisfacción del "éste es el mejor de los mundos", así como de superar esa mirada vuelta sobre sí misma (véase los realityshow) como clausura, esa endocolonización que produce un mundo sin intimidad (Virilio, 2000: 57). Esto, si tomamos en consideración a Paul Virilio, quien dice que la percepción en el mundo moderno es producto del cruce de dos quehaceres: en primer lugar, el quehacer logístico del poder militar; $y$, en segundo lugar, el de las tecnologías cinemáticas, basadas en el uso del tiempo, que hacen desaparecer lo real al sustituirlo (Virilio, 2009; Armitage, 2001: 5) o al reemplazarlo por un simulacro (Baudrillard, 1983). Se trata, en consecuencia, de reganar la mirada de la ciudad favoreciendo el lugar en vez de la mediación (la tv.).

\section{Plegar y desplegar las ciudades}

Ahora voy a referirme en específico a Las cosas nuevas, pues quisiera adelantar otra manera posible de leer la obra de Moltedo como un solo texto con muchos pliegues, de forma tal que cada pliegue se despliegue en otros prácticamente ad 
infinitum, permitiendo la variación de algún aspecto, como si el plegado funcionara como un prisma. Estos pliegues pueden ser llamados de acuerdo a la isotopía clave alrededor de la cual los recorridos significantes se levantan, la del "gran pliegue de la memoria", consistente en pensamientos que atraen al interior del ciudadano-poeta el afuera de la polis, es decir, que transforman el afuera, la ciudad exterior, los lugares citados en su poesía, en interioridad y viceversa, puesto que, por medio de los pliegues, "lo más lejano deviene interior al transformarse en lo más próximo" (Deleuze, 1987: 158). De esta manera, el quehacer poético de Moltedo, publicado en nueve libros que van desde Cuidadores (1959) hasta Las cosas nuevas (2011), se expande en un irse plegando, desplegando y replegando que conecta toda su obra como un rizoma. De acuerdo con esta lectura, no necesariamente habría un despliegue lineal de su obra, sino que ésta sería como un gran origami o un gran plegado en el que, al plegarse y desplegarse, los textos se van relacionando -por continuación, contradicción, presentación de otro aspecto, variación-con otros y, así, en dimensiones intratextuales, intertextuales y extratextuales, incluyendo formas de la oralidad en general. Esto es bastante evidente en los textos más cortos, en los que la oralidad y sus giros son claves.

De acuerdo con este argumento, podría establecer, aunque no exhaustivamente, varios pliegues que se abren a recorridos o mesetas, como, por ejemplo, las que llamaré "darse vuelta la chaqueta" (plegados 1, 7), "la espera de amor" (2, $8,21,28,30,60,68,89)$, "crimen como deporte" $(3,4,30,64,94,106)$, "saqueo" (4), "el centro es la autoridad" $(5,116)$, "memoria de la otra ciudad" $(6,15,67)$, "fusión de los opuesto" $(1,7,9,78)$, "poesía como regalo" $(2,8,10,21,30,60$, $68,98)$, "centro y periferia" $(1,7,9,61,104)$, "amor encarnado" $(2,8,10,21,30$, $60,68)$, "vacío de la ley" $(11,12,26,94)$, "despreciable poder" $(11,12,116)$, "poesía como consejo" (13,46, 82, 104), "sobre días y noches" (14, La noche, 71, 72, 75), "prohibición de la memoria" (6, 15, 48), "mensajes" (16), "contestar" (17), "poesía como protección" (18, 53), "de poeta a poeta" (19), "la transdictadura" (18, 20, 32, 35, 39, 40, 43, 53, 64, 75, 107), "corazón" (2, 8, 10, 21, 70, 73, 84, 109), "despersonalización" ( 22), "figura" ( 2, 3, 8, 10, 21, 23, 24, 25, 30, 45, 63, $84,113)$, "el otro funcionamiento" $(23,24)$, "observar y testificar" $(3,4,23,25,30$, $45,64,86,92,106)$, "poesía como espejo" $(3,23,24,25,30)$, "resistir el ruido" $(11,12,26,62,67,114)$, "impersonal cambio de signo" $(27,47,77)$, "siglas de la muerte" (29), "Ilaves" (3, 8, 30, 64), "política como comic" (31), "la ciudad como lugar de encuentro" $(32,35,39,54)$, "la ciudad como desencuentro" $(32,54)$, "el espectáculo" (1, 3, 4, 7, 9, 13, 30, 33, 38, 46, 48, 49, 52, 57, 62, 64, 67, 78, 92, 93, $95,97,99,111,112,114,115)$, "preguntar" $(34,51)$, "escribir es viajar" (32, 35, $37,39,40,54,113)$, "la escritura nace de la hoguera" (37), "ser invitado" (33, 38, 48, 57), "el mar" (32, 35, 39, 59), "muralla" (42, 35, 39, 40, 107, 108, 113), "ocultar" (41, 48), "el terror" (42), "mirar Valparaíso" $(43,107)$, "política como circo" (44), "cuidadores" $(24,45)$, "sobre cuerpos" $(13,38,46)$, "invertir" $(36,47,66,77$, 
100), "volver" (50, 105), "enamorar" (34, 51), "sobre la censura" $(18,20,53,112)$, "desapariciones" $(13,15,33,36,38,41,46,47,49,52,55,56,76,77,87,88,91$, $100,101)$, "apariciones" $(55,56,113)$, "teatro de operaciones" $(13,38,46,48,49$, $52,57)$, "retratos de pajarracos" (58, 70, 73, 96), "sobre colonización" (61), "divididos" (64, 67), "instituciones (65), "la otra ciudad" $(6,15,67,71,72,81,102,113$, 114), "preguntar" $(69,71,79,80,83)$, "poesía como conversación" (67, 69, 71, $72,79,80,81,85,90,92,103,110)$, "sobre la ceguera" $(2,8,10,21,74,84,112$, 109), "ciudad amurallada" (71, 72, 75), "el arte" (55, 76, 91), "totalizar" (7, 9, 78), "poesía como pregunta $(69,71,79,81,85)$, "poesía como apelación" $(13,82)$, "presencia" (8, 21, 30, 60, 68, 89), "visiones" (55, 76, 91, 109), "la ley" $(11,12,26$, 59, 94), "el modelo" (13, 38, 46, 48, 49, 52, 57, 93, 95, 97), "abrir" (2, 8, 10, 21, 30, 60, 68, 98), "el espectáculo de la coexistencia" (1, 7, 9, 78, 99), "esclavitud" $(9,13,15,33,36,38,41,46,47,49,52,77,100,101,104)$, "monstruos" $(32,35$, $39,107,108)$, "lugar y aparición" $(24,35,40,86,113)$, "sustituir" (115). Y así podría plegar estos recorridos con la obra toda de Moltedo.

¿Qué quiero decir con esto? Simplemente, que los plegados articulan la continuidad de los parques que nuestra tradición occidental nos ha enseñado a negar para ver sólo el parcelamiento, el coto, la negación de la relación, la isla, ya que nos hemos enseñado a aislar, cortar, separar en el lenguaje, para así lograr creer que hemos aprendido algo. Leer plegando es un ejercicio de otro tipo de totalidad abierta a lo que está afuera, a lo que traemos a la mano, a "la realidad nunca vista" (98) que nos menciona Moltedo. Pero ahora volveré a la cuestión del vivir a que me referí más arriba.

\section{¿Qué es cuidar las ciudades?}

Dice Heidegger que el lugar de la obra de arte es un Stätte, una casa, un hogar, y que el "hogar" está inscrito en la misma obra de arte (1971: 46). Esta es una referencia al carácter circular del quehacer humano. He aquí la pertinencia de la escritura de Moltedo, que constituye nuestro suelo, la tierra, la verdad que emerge de nuestro vivir, de nuestro hacer el reino de este mundo. La obra de arte, en consecuencia, pertenece al dominio que ella trae a la mano y constituye su verdad, que Moltedo hace residir en el corazón. El corazón es el dominio en el cual la verdad ocurre, puesto que la verdad de la ciudad interior (la civitas) debe manifestarse en el cuidado de la ciudad exterior (la polis). Cuidar consiste en mantener este balance de la dualidad (no de la dicotomía). Cuidar es fundamentalmente un quehacer poético, pero no sólo del poeta, sino de todo aquel que es ciudadano. Pero esto es justamente lo que está bajo ataque por las fuerzas a que refería Ferlinguetti (2001) más arriba, ya que nunca ha sido el propósito de los déspotas que la ciudad funcione, sino que el odio, la competición, la lucha del uno contra el otro tome lugar. Para referirse a esto, se habla de la transdictadura, es 
decir, de la prolongación de la dictadura por otros medios. Aquí es donde el poeta nombra la mentira, la hipocresía, el reino de la imagen, del sustituto (Virilio, 2009), del simulacro (Baudrillard, 1983), y esa realidad de segundo grado que se llama la sociedad del espectáculo (Debord, 1976); "bruma" que va minando tanto el corazón del ciudadano como su ciudad. ¿Cómo impacta la irrealidad en la ciudad? El impacto intensivo de esta irrealidad del espectáculo en la configuración de la polis (ciudad), tanto como en la civitas (subjetividad), es aquello de lo que hace la crónica el poeta. Cuidar consistirá, por lo tanto, en el activo rechazo del ruido del espectáculo y en el cuidado de la memoria cultural (situada tanto en la ciudad como en el corazón). El cuidado de la ciudad es absolutamente necesario, ya que con ello la experiencia real, material, manifestada en los quehaceres diarios en la ciudad, no puede desaparecer si queremos seguir siendo lo que somos. Es una lucha contra la desaparición del lugar como también de la experiencia amarrada al lugar de nuestra enunciación. En este sentido, el trabajo del poeta es un trabajo desde aquí y en el ahora. En esto reside la originalidad de Moltedo: en revelarnos, en sus plegados, el lugar donde somos y estamos. Si recordamos lo que ha sido dicho más arriba, el contexto general de este quehacer es la lucha contra la contracción del espacio-tiempo en un sólo modelo de existencia global, es la lucha contra la monocultura de la muerte, es decir, contra la repetición del mismo diseño de existencia en una cultura del consumo de las imágenes en la que nos vemos inmersos obligatoriamente en la sociedad del espectáculo. Contra esta obligación, la mirada poética se dirige hacia la reapropiación de los ritmos de vida del cuidado y busca los signos de esa vida más allá de los muros levantados por la dictadura y su extensión en la transdictadura, para no quedar prendados para siempre de las imágenes de la pantalla y no volvernos picnolépticos (Virilio, 1997), zombies, de su eterno presente. Contra la contracción del tiempo que lleva a la inercia de sentirse "lanzados al espacio", de haber roto con los lazos de la tierra, de nuestra tierra, de volar en el vacío -esa utopía del homo conquero de hoy y el tan particular y pobre racionalismo a que obligan su lógica y diseños-, de no tener que sufrir el vértigo de la gravitación terrestre, de la gravitación de la particularidad de nuestro lugar, de nuestra polis, y de poder "flotar" en el vacío sin más ataduras al tirón de la tierra ni a la historia; es decir, contra la fantasía de creernos universales porque hemos al fin superado nuestras raíces y ahora somos, ya no "los ingleses de Sudamérica", sino algo más grande e infinito que aún no conocemos, pero que amamos con el arrebato que nos da la seguridad de nuestra ceguera; contra esta locura racional que alimenta la ceguera de los que se llaman a sí mismos líderes; el poeta nos invita a mirar de otra manera, con un poder que atraviese las murallas del espectáculo para volver a ver el horizonte que nos espera más allá de la imagen de farándula que proyectamos. Para terminar, la gran cuestión que nos presenta Moltedo es la de la mirada, la de querer mirar de otra 
manera, potenciando nuestros sentidos y rechazando la mediación que nos separa de nuestras dos ciudades, la exterior y la interior. Esta es la resistencia a la que llama Moltedo: resistir la flotación postmoderna de la sociedad del espectáculo y del "todo vale". Éste es el reino de nuestro mundo.

\section{Referencias}

Andreotti, Libero; Costa, Xabier; eds. (1996). Theory of the Derive and Other Situationist Writings on the City. Barcelona: MACBA.

Armitage, John, ed. (2001). Virilio Live. Selected Interviews. Londres, Thousand Oaks, Nueva Delhi: SAGE.

Baudrillard, Jean (1983). Simulations. Nueva York: Semiotext(e).

Benjamin, Walter (1982). "Experiencia y pobreza". Discursos interrumpidos I. Madrid: Taurus.

Castillo, Gabriel (2003). Las estéticas nocturnas: ensayo republicano y representación cultural en Chile e Iberoamérica. Santiago: Colección Aisthesis 30 años, UC.

Chihuailaf, Elicura (1999). Recado confidencial a los chilenos. Santiago: LOM.

Debord, Guy (1976). La sociedad del espectáculo. Madrid: Castellote.

Deleuze, Gilles (1993). The Fold. Leibniz and the Baroque. London: Athlone.

Droguett, Carlos (2001). Matar a los viejos. Santiago: LOM.

Ferlinghetti, Lawrence (2001). San Francisco Poems. San Francisco: City Lights.

Flores, Manuel (SF). Tesis de PhD, sin presentar.

Gómez de Silva, Guido (1998). Breve diccionario etimológico de la lengua castellana. México: FCE.

Heidegger, Martin (1971). "The Origin of the Work of Art". Poetry, Language, Thought. New York: Harper \& Row.

Herrera, Marco (1997). “Escribo para no perderlo todo', Entrevista a Ennio Moltedo". El Mercurio de Valparaíso, domingo 23 de noviembre. Recuperado el 16 de noviembre de 2016 de http://www.letras.s5.com/jc020404.htm.

Holas, Sergio (2008). "Intenso vivir. Contra el desarraigo: vida y creatividad en Violeta Parra". IXQUIC. Revista Hispánica Internacional de Análisis Literario y Cultural, Monográfico dedicado a Violeta Parra, n. 9. 24-36.

Manns, Patricio (1999). Chile: una dictadura permanente (1811-1999). Santiago: Sudamericana.

Maturana, Humberto; Dávila, Ximena (2008). Habitar humano en seis ensayos de biologíacultural. Santiago: J. C. Sáez. 
Maturana, Humberto (1995). "Biología y violencia". En: Coddou, Fernando et al. Violencia en sus distintos ámbitos de expresión. Santiago: Dolmen. 69-88.

(1993). "Conversaciones matrísticas y patriarcales". En: Maturana, Humberto; Verden-Zöller, Gerda. Amor y juego. Fundamentos olvidados de lo humano. Desde el patriarcado a la democracia. Santiago: Instituto de Terapia Cognitiva. 19-70.

McDonough, Tom, ed. (2009). The Situationists and the City. London \& New York: Verso.

Mignolo, Walter (2000). Local Histories/Global Designs. Coloniality, Subaltern Knowledges, and Border Thinking. Princeton: Princeton University.

Moltedo, Ennio (1999). La noche. Viña del Mar: Altazor. (2011). Las cosas nuevas. Viña del Mar: Altazor.

Redhead, Steve (2004). Paul Virilio. Theorist for an Accelerated Culture. Edinburgh: Edinburgh University.

Sadler, Simon (1998). The Situationist City. Cambridge: MIT.

Virilio, Paul (2009). The Aesthetics of Dissapearance. New York: Semiotext(e). (2000). The Information Bomb. London: Verso. (1997). Open Sky. London \& New York: Verso. (1989). War and Cinema. The Logistics of Perception. London: Verso. 